\title{
SIGNIFICANCE OF MONOCYTE CHEMOATTRACTANT PROTEIN-1, THYROID HORMONES AND OTHER CLINICAL MANIFESTATIONS IN IRAQI PATIENTS WITH POLYCYSTIC OVARIAN SYNDROME
}

\author{
ISRAA BURHAN RAOOF ${ }^{*}$, ASEEL GHASSAN DAOUD ${ }^{2}$, RAGHAD ABDULMAHDI MOHSIN ${ }^{3}$ \\ ${ }^{1}$ Department of Clinical Laboratory Science, College of Pharmacy, University of Al-Mustansiriyah, Iraq. ${ }^{2}$ Department of Clinical Laboratory \\ Science, College of Pharmacy, University of Al-Mustansiriyah, Iraq. ${ }^{3}$ Department of Pharmacology and Toxicology, College of Pharmacy, \\ University of Al-Mustansiriyah, Iraq. Email: israaburhan@uomustansiriyah.edu.iq
}

Received: 10 May 2018, Revised and Accepted: 13 June 2018

ABSTRACT

Objective: Polycystic ovarian syndrome (PCOS) is a complex disease occurred throw genital period of women depends on the age, genetic factors, and ethnicity. Monocyte Chemoattractant Protein-1 (MCP-1) has been implicated in the metabolic disturbances and menstrual irregularities.

Methods: In the biochemical test, the blood was collected in plain tubes then separated by centrifugation. Serum was collected in test tubes then, MCP, haemoglobin ( $\mathrm{Hb}$ ), packed cell volume (PCV), fasting blood glucose (FBG), urea, creatinine, prolactin, testosterone, luteinizing hormone (LH), follicle stimulating hormone (FSH), T3, T4, and thyroid-stimulating hormone (TSH) were determined by enzyme-linked immune-sorbent assay and relevant clinical features were collected simultaneously in all subjects.

Results: The results showed no significant increased in means of age, body mass index in PCOS women (patients) when compared with healthy subjects (control groups) also there was no significant decreased in levels of $\mathrm{Hb}$, PCV while increased in FBG, urea and creatinine in PCOS women when compared with healthy subjects. In addition, mean of LH and $17 \beta$-Estradiol were no significant increased except the significantly increased in the ratio of LH/FSH, prolactin, and testosterone, while FSH was significantly decreased in PCOS women when compared with healthy subjects. Levels of triiodothyronine (T3) and thyroxine (T4) were found significantly decreased while an increased level of TSH when compared with healthy subjects. Finally, MCP-1 was showed significantly increased in PCOS women when compared with healthy subjects.

Conclusions: It can be concluded that PCOS women might suffer from changes in the levels of MCP-1(an inflammation marker). Besides, it was detected that TSH might be responsible related metabolic disturbances could be related to TSH and MCP which can be considered as relevant features in such disturbances.

Keywords: Polycystic ovarian syndrome, Reproductive hormones, Thyroid hormones, Monocyte chemoattractant protein-1.

(c) 2018 The Authors. Published by Innovare Academic Sciences Pvt Ltd. This is an open access article under the CC BY license (http://creativecommons. org/licenses/by/4. 0/) DOI: http://dx.doi.org/10.22159/ajpcr.2018.v11i8.27238

\section{INTRODUCTION}

Polycystic ovarian syndrome (PCOS) is endocrine disease causes infertility, acne, hirsutism, and irregular periods, with insulin resistance [1,2]. The follicles in each ovarian outside about 10-15 with most of them generally small or immature than average caused infertility [3]. Many factors are thought to be responsible for its pathophysiology such as ethnicity, genetic, multiple endocrine, and metabolic abnormalities [4,5]. In addition to, environmental factors such as physical activity, lifestyle, and diet [6]. Insulin resistance, hyperandrogenemia, and PCOS are associated with pro-inflammatory status caused by oxidative stress [7]. The production of reactive oxygen species is increased by hyperglycemia associated with PCOS [8] Elevated androgen which leads to overproduction of gonadotropins particularly luteinizing hormone (LH) [9] together with high insulin level leads to follicular growth arrest that initiates anovulation [10]. Anovulation in PCOS women is often associated with estradiol $\left(\mathrm{E}_{2}\right)$ secretion and progesterone production [11]. PCOS women present with phenotypes according to ESHRE guidelines [12] endocrine irregularities including abnormally high levels of LH, follicle stimulating hormone (FSH), FSH/ LH, prolactin, estradiol, testosterone, and insulin resistance $[13,14]$. Moreover, PCOS women may be presented with nodular goiter associated with this syndrome $[15,16]$. Many studies showed disorder in tri-iodothyronine (T3) level and anti-thyroid peroxidase antibody in PCOS patients [17]. Hypothyroidism has been associated increase of sex hormone-binding globulin levels [18] these actions effected on the osteoblast cells [19]. The treatment aimed in the regulation of menses and recover of fertility [20]. The first-line therapy is the lifestyle modification, oral pharmacological agents such as clomiphene and metformin, which lower the level of insulin resistance and induce ovulation [21]. Besides, it was found that Vitamin D and metabolic modulations [22]. Monocyte chemoattractant protein-1 (MCP-1) and Macrophage inflammatory protein-1 closely related to metabolic syndrome presence of chronic low-grade inflammation in women with this syndrome are emerging [23]. MCP-1 is expressed and secreted by adipocyte, which has been reported to be involved in the recruitment and activation of peripheral blood leukocytes in adipose tissue and the induction of systemic insulin resistance [24].

\section{PATIENTS AND METHODS}

About 25 PCOS women (patients) and 25 healthy subjects (control group) were enrolled in this study. Blood was collected from Kamal- Al SamarraiHospital/Baghdad. In the biochemical test, the blood was separated by centrifugation then in test tubes which were marked with names of patients and control group then frozen at $-20^{\circ} \mathrm{C}$. Then, $\mathrm{MCP}$, hemoglobin (Hb), packed cell volume (PCV), fasting blood glucose (FBG), urea, creatinine, prolactin, testosterone, LH, FSH, T3, T4, and thyroid-stimulating hormone (TSH) were determined by enzymelinked immune-sorbent assay and relevant clinical features were collected simultaneously in all subjects.

Statistical analysis

The results were expressed as Mean \pm standard deviation with $\mathrm{p}<0.05$ indicated that there was a significant difference when comparing between PCOS women and healthy subjects using SPSS-18 program 
Microsoft. Correlation coefficients test was done between groups; the significant correlation between values was expressed as $\mathrm{p}<0.05$.

\section{RESULTS AND DISCUSSION}

Patients with PCOS suffered irregularity in a menstrual cycle which usually either amenorrhea or oligomenorrhea, patients with PCOS suffered from symptoms such as depression, acne, and hirsutism in varying intensity as shown in Table 1 .

In this study, the results showed no significant increase in the means of age and body mass index in patients when compared with healthy subjects as shown in Table 2 .

There was no significant decrease in the serum levels of $\mathrm{Hb}$ and PCV while no significant increase in FBG, urea, and creatinine in PCOS patients when compared with the control group as shown in Table 3

In addition, mean of $\mathrm{LH}$ and $17 \beta$-Estradiol were no significantly increased except the significant increase in the ratio of LH/FSH, prolactin, and testosterone, while FSH was significantly decreased in PCOS women when compared with healthy subjects as shown in Table 4 .

Levels of triiodothyronine (T3), thyroxine (T4) were found to be significantly decreased, however, a significant increase in the level of TSH was found in patients when compared with healthy subjects. Finally, a significant increase was detected in the level of MCP-1 in patients when compared with healthy control as shown in Table 5 and Fig. 1.

Table 1: General description of PCOS women

\begin{tabular}{ll}
\hline Symptoms & $\mathbf{n}(\%)$ \\
\hline Amenorrhea & $7(28)$ \\
Oligomenorrhea & $14(56)$ \\
Menstrual irregularity & $21(84)$ \\
Acne & $14(56)$ \\
Depression & $16(64)$ \\
Hirsutism & $20(80)$ \\
\hline
\end{tabular}

PCOS: Polycystic ovarian syndrome

Table 2: Clinical characteristics for PCOS women and control groups

\begin{tabular}{llll}
\hline Parameters & Mean \pm SD & \multicolumn{2}{c}{$\mathbf{p}$} \\
\cline { 2 - 3 } & Controls & Patients & \\
\hline Age & $24.9 \pm 5.646$ & $29.4 \pm 5.680$ & 0.6 \\
BMI $\left(\mathrm{Kg} / \mathrm{m}^{2}\right)$ & $23.884 \pm 2.306$ & $25.101 \pm 4.546$ & 0.8 \\
\hline
\end{tabular}

Significant using SPSS for two independent means of significance $*(p \leq 0.05)$,

$* *(\mathrm{p} \leq 0.01)$. PCOS: Polycystic ovarian syndrome, SD: Standard deviation,

BMI: Body mass index

Table 3: PCV, Hb, FBG, urea, and creatinine levels in PCOS and control groups

\begin{tabular}{llll}
\hline Parameters & \multicolumn{2}{l}{ Mean \pm SD } & p \\
\cline { 2 - 3 } & Controls & Patients & \\
\hline PCV (\%) & $39.933 \pm 1.830$ & $38.8 \pm 3.707$ & 0.45 \\
Hb & $13.493 \pm 0.705$ & $12.933 \pm 0.983$ & 0.16 \\
FBG mmol/l & $4.763 \pm 0.370$ & $5.066 \pm 0.601$ & 0.82 \\
Urea mmol/l & $21.266 \pm 1.624$ & $23.41 \pm 4.017$ & 0.08 \\
Creatinine mg/dl & 0.9800 .1321 & $1.008 \pm 0.164$ & 0.64 \\
\hline
\end{tabular}

Significant using SPSS for two independent means of significance* $(\mathrm{p} \leq 0.05)$,

** $(p \leq 0.01)$. PCOS: Polycystic ovarian syndrome, SD: Standard deviation,

PCV: Packed cell volume, Hb: Hemoglobin, FBG: Fasting blood glucose
There was a significant correlation between MCP-1 and other clinical markers demonstrated in Table 6 and Fig. 2-5.

The increased risk of Type 2 diabetes mellitus (DM) among women with PCOS was clarified in a study which was demonstrated to be higher compared with healthy subjects, impaired glucose tolerance, insulin resistance of tissues (adipose tissue, liver, and skeletal muscle), and metabolic syndrome in PCOS women, all these together with irregularities in the menstrual cycle (amenorrhea or oligomenorrhea) [25,26]. PCOS can be considered a genetic disorder just like T2 DM [27], and it has been occurred in one of each five women within the reproductive age $[28,29]$. On the other hand, it was found that high Estradiol levels may affect the thyroid cells [30]. In hyperandrogenemia, Testosterone level measurement is very important [31]. Besides, it was predicted that perpubertal obese girls with hyperandrogenemia had abnormal fasting insulin [32], in addition obese patients have higher estrogens levels which lead to hirsutism and FSH inhibition because excess adipose tissue in those patients can convert androstenedione to estrone and testosterone to estradiol through its aromatase enzyme [33]. Mec Cartney demonstrated that women with PCOS having higher LH pulse abundance and frequency in addition to abnormal LH secretions. Other studies found that high insulin levels in $75 \%$ of PCOS women may lead to hypothalamic pituitary-ovarian axis abnormalities which may result in an elevation in LH levels in those patients. On the other hand, it was demonstrated that FSH levels in those patients were significantly lower than in healthy subjects, these findings agree with some other studies, where it is thought that adipose tissue in PCOS patients by increasing androstenedione levels, it will lead to LH stimulation and FSH inhibition at the same time [34]. In women at the reproductive age who had thyroid

Table 4: Testosterone, FSH, LH, prolactin, and estradiol levels in PCOS and Control groups

\begin{tabular}{|c|c|c|c|}
\hline \multirow[t]{2}{*}{ Parameters } & \multicolumn{2}{|l|}{ Mean \pm SD } & \multirow[t]{2}{*}{$\mathbf{p}$} \\
\hline & Controls & Patients & \\
\hline $\mathrm{LH} \mathrm{mlU} / \mathrm{ml}$ & $5.233 \pm 5.744$ & $6.966 \pm 2.315$ & 0.3 \\
\hline $\mathrm{FSH} \mathrm{mlU} / \mathrm{ml}$ & $7.74 \pm 4.347$ & $4.212 \pm 2.478$ & $0.009^{* *}$ \\
\hline $\mathrm{LH} / \mathrm{FSH}$ & $0.720 \pm 0.649$ & $1.925 \pm 1.217$ & $0.005^{* *}$ \\
\hline Prolactin ng/ml & $14.084 \pm 11.836$ & $20.821 \pm 5.270$ & $0.01^{* *}$ \\
\hline $17 \beta$-estradiol pg/ml & $31.733 \pm 14.598$ & $38.28 \pm 6.924$ & 0.13 \\
\hline Testosterone ng/ml & $0.21 \pm 0.107$ & $3.990 \pm 5.853$ & $0.026^{*}$ \\
\hline
\end{tabular}

Table 5: T3, T4, TSH, MCP levels in PCOS and control groups

\begin{tabular}{llll}
\hline Parameters & \multicolumn{2}{c}{ Mean \pm SD } & p \\
\cline { 2 - 3 } & Controls & Patients & \\
\hline $\mathrm{T}_{3} \mathrm{nmol} / \mathrm{ml}$ & $1.243 \pm 0.248$ & $1.013 \pm 0.199$ & $0.02^{*}$ \\
$\mathrm{~T}_{4} \mathrm{nmol} / \mathrm{ml}$ & $94.190 \pm 9.755$ & $81.786 \pm 15.19$ & $0.01^{* *}$ \\
$\mathrm{TSH} \mathrm{mulu} / \mathrm{ml}$ & $1.268 \pm 0.655$ & $2.128 \pm 1.106$ & $0.02^{*}$ \\
$\mathrm{MCP}-1 \mathrm{ng} / \mathrm{l}$ & $1.975 \pm 0.716$ & $3.115 \pm 0.681$ & $0.007^{* *}$ \\
\hline
\end{tabular}

Significant using SPSS for two independent means of significance * $(\mathrm{p} \leq 0.05)$,

**(p $\leq 0.01)$. MCP: Monocyte chemoattractant protein, TSH: Thyroid-stimulating hormone, PCOS: Polycystic ovarian syndrome

Table 6: Correlation coefficient between clinical markers in patients with PCOS

\begin{tabular}{lll}
\hline Variable & Correlation & Sig.(2-tail) \\
\hline Testosterone and MCP & 0.752 & $0.002^{* *}$ \\
$17 \beta$-Estradiol and T4 & -0.654 & $0.03^{*}$ \\
$17 \beta$-Estradiol and Prolactin & -0.606 & $0028^{*}$ \\
Creatinine and urea & 0.758 & $0.001^{* *}$ \\
\hline
\end{tabular}

Significant using SPSS for two independent means of significance $*(p \leq 0.05)$, $* *(\mathrm{p} \leq 0.01)$ 


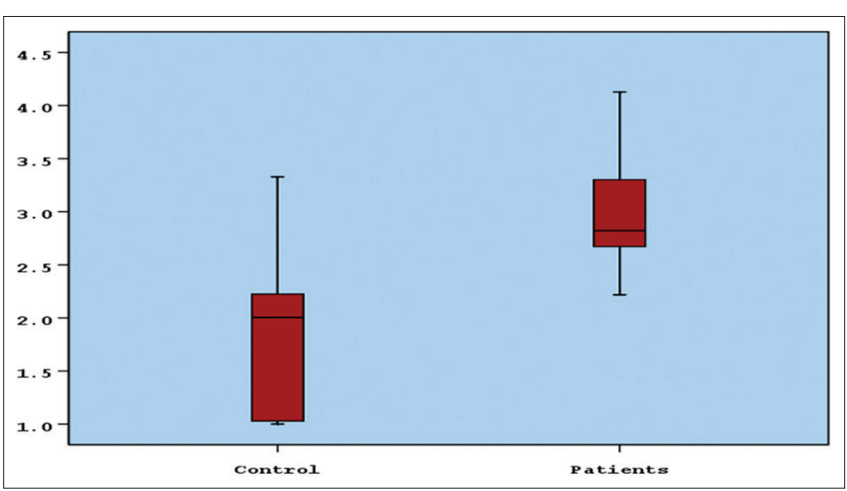

Fig. 1: The boxplot graph of monocyte chemoattractant protein of controls and patients

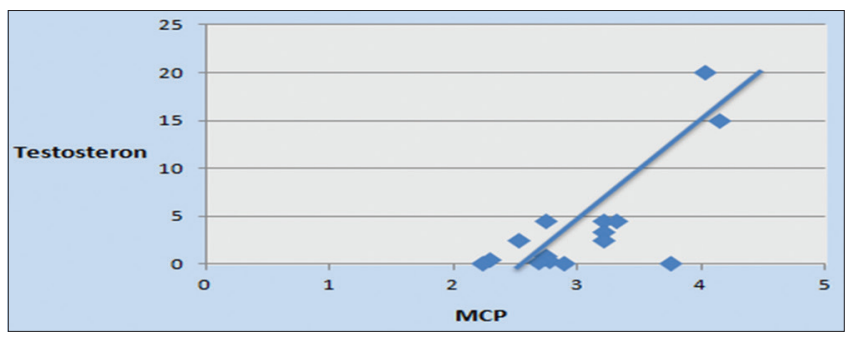

Fig. 2: Relationship between monocyte chemoattractant protein and testosterone in women with polycystic ovarian syndrome

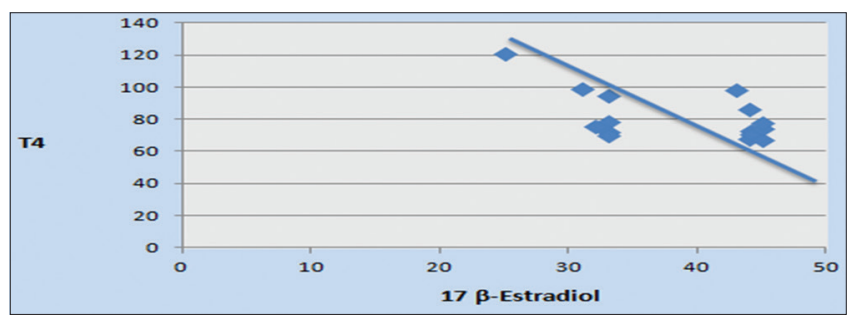

Fig. 3: Relationship between $17 \beta$-Estradiol and T4 in women with polycystic ovarian syndrome

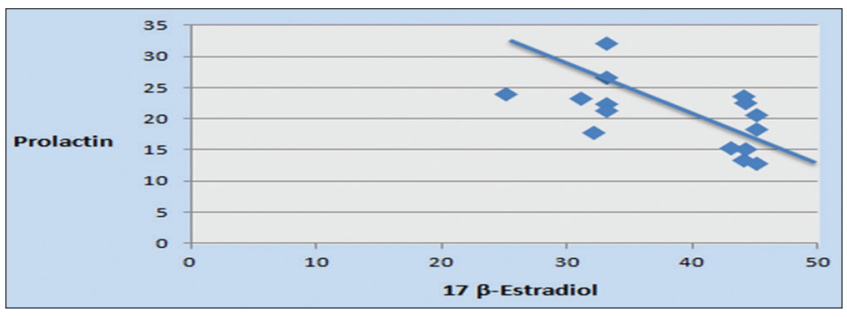

Fig. 4: Relationship between17 $\beta$-estradiol and prolactin in women with polycystic ovarian syndrome

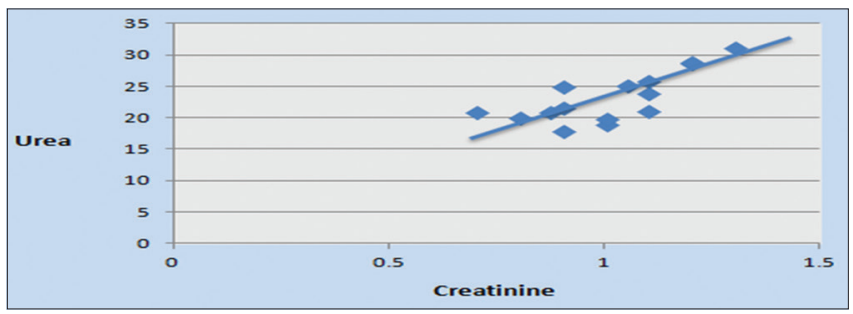

Fig. 5: Relationship between creatinine and urea in women with polycystic ovarian syndrome disorders, LH/FSH ratio was higher due to the presence of thyroid antibody, which may interact with the ovaries through both direct effects on ovarian function and autoimmune pathways besides chromosome $\mathrm{X}$ abnormalities [35]. A profound relationship was found between thyroid dysfunction (thyroid volume) and PCOS [36]. The mechanism for this relationship is still unclear; however, it might be due to the changes occur in LH levels that increased about $50 \%$ of PCOS women while FSH levels were either normal or decreased [37]. A recent study demonstrated that metabolic changes responsible for the significant increment in total thyroxine (TT4), total triiodothyronine (TT3), and TSH, besides, it was found that total testosterone and TSH levels were significantly increased in those patients compared with healthy controls $[38,39]$. This high level of TSH may lead to disorder of FSH receptor [40]. Those PCOS women with higher TSH show metabolic syndrome complications [41]. On the other hand, recent findings found that ovarian cysts may be produced by hypothyroidism and that polycystic behavior of the ovaries was relieved by treatment with thyroxine, so, as a conclusion, primary hypothyroidism can lead to PCOS-like ovaries [42]. One of the mechanisms that lead to the infiltration of leukocytes into sites of inflammatory responses is the production of chemotactic molecules that diffuse out from the site of release and form concentration gradient to which leukocytes respond and migrate, serum from women with PCOS, when compared to serum from controls, induced significantly increased expression of MCP-1 in THP-1 human monocyte cell line. Several reviews concerning the role of MCP-1 in the pathogenesis of many inflammatory diseases are already available elsewhere. Macrophages play important roles in defense by presenting Ag to lymphocytes or by participating in efferent limb immune responses as effecter or secreting cytokines. Macrophages infiltrating sites of inflammation are derived from blood monocytes, which are attracted by chemotactic factors produced at inflammatory sites [43].

\section{CONCLUSION}

From the current study, it can be concluded that PCOS women might suffer from low-grade chronic inflammation as a result of changes in the levels of MCP-1(an inflammation marker). Besides, it was detected that TSH might be responsible for all of the irregularities in the levels of sex hormones in such patients. Furthermore, PCOS-related metabolic disturbances could be related to TSH and MCP which can be considered as relevant features in such disturbances.

\section{Recommendations}

In subjects who have high risk of developing PCOS at a very young age, it is important to keep in mind all the abnormalities that could be occurred in metabolic (such as adiposity and hyperinsulinemia) and endocrine (includes adrenal and ovarian) functions during this disease and to find reliable markers that can give a clear diagnosis of such disorders in early childhood prior the development of PCOS

\section{AUTHOR'S CONTRIBUTIONS}

ISRAA BURHAN RAOOF

1. Write the Introduction, Patients and Methods and Conclusion

2. Measurement of parameters in hospital.

\section{ASEEL GHASSAN DAOUD}

1. Work of Turn tin of article

2. Sample collection; Write the Results and Discussion and Recommendation

\section{RAGHAD ABDULMAHDI MOHSIN}

1. Work of Statistical analysis of article

2. Complete collection of sample; write Abstract and Arrangement of References.

\section{REFERENCES}

1. Dargham S, Ahmed L, Kilpatrick ES, Atkin SL. The prevalence and metabolic characteristics of polycystic ovary syndrome in the Qatari 
population. Plos One 2017;12:1-7.

2. Anbu J, Jayaraman A, Krishnan S, Shivalingappa SK, Reddy RP, Nandihalli VB, et al. Effect of Sargassum ilicifolium on ovogenesis in polycystic ovary syndrome-induced rats. Asian J Pharm Clin Res 2016;9:127-31.

3. Al-Deresawi MS, AlFaisal AH. Detection of five substitution TPO mutations in polycystic ovary syndrome (PCOS) and thyroid hormones disturbance patients. J Biotechnol Res Center 2014;8:5-15.

4. Zaki M, Hassan N, El-Bassyouni HT, Kamal S, Basha W, Azmy O, et al. Association of the Pro12Ala polymorphism with the metabolic parameters in women with polycystic ovary syndrome. Open Access Maced J Med Sci 2017:5:275-80.

5. El Hayek S, Bitar L, Hamdar LH, Mirza FG, Daoud G. Poly cystic ovarian syndrome: An updated overview. Front Physiol 2016;7:124.

6. De Leo V, Musacchio MC, Cappelli V, Massaro MG, Morgante G, Petraglia F. Genetic, hormonal and metabolic aspects of PCOS: An update. Reprod Biol Endocrinol 2016;14:38.

7. Murri M, Luque-Ramírez M, Insenser M, Ojeda-Ojeda M, EscobarMorreale HF. Circulating markers of oxidative stress and polycystic ovary syndrome (PCOS): A systematic review and meta-analysis. Hum Reprod Update 2013;19:268-88.

8. Sortino MA, Salomone S, Carruba MO, Drago F. Polycystic ovary syndrome: Insights into the therapeutic approach with inositols. Front Pharmacol 2017;8:1-13.

9. Højlund K. Metabolism and insulin signaling in common metabolic disorders and inherited insulin resistance. Dan Med J 2014;61:B4890.

10. Cadagan D, Khan R, Amer S. Thecal cell sensitivity to luteinizing hormone and insulin in polycystic ovarian syndrome. Reprod Biol 2016;16:53-60.

11. Homer MV, Rosencrantz MA, Shayya RF, Chang RJ. The effect of estradiol on granulosa cell responses to FSH in women with polycystic ovary syndrome. Reprod Biol Endocrinol 2017;15:1-6.

12. Al-Jefout M, Alnawaiseh N, Al-Qtaitat A. Insulin resistance and obesity among infertile women with different polycystic ovary syndrome phenotypes. Sci Rep 2017;7:1-9.

13. Sirmans SM, Pate KA. Epidemiology, diagnosis, and management of polycystic ovary syndrome. Clin Epidemiol 2013;6:1-13.

14. Pergialiotis V, Konstantopoulos P, Prodromidou A, Florou V, Papantoniou N, Perrea DN, et al. Managements of endocrine disease: The impact of subclinical hypothyroidism on anthropometric characteristics, lipid, glucose and hormonal profile of PCOS patients: A systematic review and meta-analysis. Eur J Endocrinol 2017;176:25- 9 .

15. Karaköse M, Gungunes A, Cakal E, Ozbek M, Delibasi T. Frequency of nodular goiter and autoimmune thyroid disease and association of these disorders with insulin resistance in polycystic ovary syndrome. J Turk Ger Gynecol Assoc 2017;18:85-9.

16. Mohammed S, Awooda HA, Rayis DA, Hamdan HZ, Adam I, Lutfi MF, et al. Thyroid function/antibodies in Sudanese women with polycystic ovarian disease. Obstet Gynecol Sci 2017;60:187-92.

17. Sinha U, Sinharay K, Saha S, Longkumer TA, Baul SN, Pal SK, et al. Thyroid disorders in polycystic ovarian syndrome subjects: A tertiary hospital based cross-sectional study from Eastern India. Indian J Endocrinol Metab 2013;17:304-9.

18. Hennessey J, Espaillat R. Diagnosis and management of subclinical hypothyroidism in elderly adults: A review of the literature. J Am Geriatr Soc 2015;63:1663-73.

19. Katulski K, Czyżyk A, Mẹczekalski B. Bone mineral density in women with polycystic ovary syndrome. J Endocrinol Invest 2014;37:1219-24.

20. Kumar A, Naidu JN, Satyanarayana U, Ramalingam K, Anitha M. Metabolic and endocrine characteristics of indian women with polycystic ovary syndrome. Int J Fertil Steril 2016;10:22-8.

21. Al-Ruthia YS, Al-Mandeel H, Al-Sanawi H, Mansy W, Al-Gasem R, Al-Mutairi L, et al. Ovulation induction by metformin among obese versus non-obese women with polycystic ovary syndrome. Saudi Pharm J 2017;25:795-800.
22. Aghadavod E, Mollaei H, Nouri M, Hamishehkar H. Evaluation of Relationship between body mass index with Vitamin D receptor gene expression and Vitamin D levels of follicular fluid in overweight patients with polycystic ovary syndrome. Int J Fertil Steril 2017;11:105-11.

23. Duleba AJ, Dokras A. Is PCOS an inflammatory process? Fertil Steril 2012;97:7-12.

24. Zaica R. MCP-1 (monocyte chemotactic protein-1) and harpin molecules in inflammation processes 3T. Bio Med 2014;44:213-7.

25. Julie T. Polycystic ovary syndrome: Why are women at increased risk of Type 2 diabetes? J Diabetes Nurs 2016;20:92-7.

26. Jesintha M. Genetic variations in polycystic ovarian syndrome disease. Asian J Pharm Clin Res 2015;8:1-6.

27. Belinda G. Polycystic ovary syndrome (PCOS) - From in utero to menopause. Diabetes Obes Int J 2016;1:1-6.

28. Azziz R. Introduction: Determinants of polycystic ovary syndrome. Fertil Steril 2016;106:4-5.

29. Joham AE, Hutchison SK, Harrison CL. Polycystic ovary syndrome, obesity, and pregnancy. Semin Reprod Med 2016;34:93-101.

30. Sahin M, Demircioglu D, Oguz A, Tuzun D, Sarica MA, Inanc E, et al. Does insulin resistance increase thyroid volume in patients with polycystic ovary syndrome? Arch Endocrinol Metab 2017;61:145- 51

31. Witchel SF, Oberfield S, Rosenfield RL, Codner E, Bonny A, Ibáñez L, et al. The diagnosis of polycystic ovary syndrome during adolescence. Horm Res Paediatr 2015;83:376-89.

32. Ahmed M. Polycystic ovarian syndrome: Insights into pathogenesis, diagnosis, prognosis, pharmacological and non-pharmacological treatment. Kabel J Pharma Rep 2016;1:1-5.

33. Alvina R, Kansra MD. Polycystic ovary syndrome in adolescents. JCOM 2016;23:233-9.

34. AlFaisal AH, Al-Deresawi MS. The correlation between thyroid hormones, reproductive hormones, body mass index (BMI) and hirsute in Iraqi women with polycystic ovary syndrome (PCOS). J Univ Anbar Pure Sci 2013;7:1-6.

35. Zou S, Sang Q, Wang H, Feng R, Li Q, Zhao X. Common genetic variation in CYP1B1 is associated with concentrations of T(4), FT(3) and FT(4) in the sera of polycystic ovary syndrome patients. Mol Biol Rep 2013;40:3315-20.

36. Abd El-Hafez HA, Elrakhawy MM, El-Aziz SA, El-Eshmawy MM. Thyroid function and volume are associated with anthropometric measurements and insulin resistance in Egyptian women with polycystic ovary syndrome. J Diabetes Metab 2013;4:1-5.

37. Legro RS, Arslanian SA, Ehrmann DA, Hoeger KM, Murad MH, Pasquali R, et al. Endocrine society. Diagnosis and treatment of polycystic ovary syndrome: An endocrine society clinical practice guideline. J Clin Endocrinol Metab 2013;98:4565-92.

38. Yin D, Ruan X, Tian X, Du J, Zhao Y, Cui Y, et al. The relationship between thyroid function and metabolic changes in Chinese women with polycystic ovary syndrome. Gynecol Endocrinol 2017;33:332-5.

39. Lan C, Tan Y, Cao P. Relationship of thyroid stimulating hormone with sex hormones in patients with polycystic ovary syndrome: A single-center, retrospective observational study. Int J Clin Exp Pathol 2017:10:5989-93

40. Singla R, Gupta Y, Khemani M, Aggarwal S. Thyroid disorders and polycystic ovary syndrome: An emerging relationship. Indian J Endocrinol Metab 2015;19:25-9.

41. Homeira R, Asghar S, Mahmoud A, Seyed M, Fahimeh R, Hajieh S. Association of thyroid stimulating hormone in women with poly cystic ovary syndrome and non poly cystic ovary syndrome with insulin resistance. Int J Pharm Technol 2016;8:11634-41.

42. Danfeng D, Xuelian L. The relationship between thyroiditis and polycystic ovary syndrome: A meta-analysis. Int J Clin Exp Med 2013;6:880-9.

43. Teizo Y. The production of monocyte chemoattractant protein-1 (MCP 1)/CCL2 in tumor microenvironments. Cytokine 2017;98:71-8. 